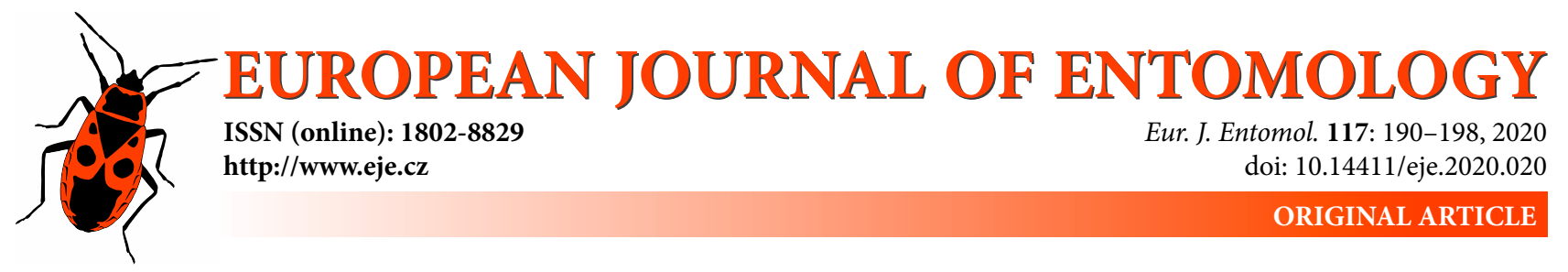

\title{
Influence of a diet containing tobacco on the biology of Ephestia kuehniella (Lepidoptera: Pyralidae) and its parasitoid Habrobracon hebetor (Hymenoptera: Braconidae)
}

\author{
Cleder PEZZINI ${ }^{1,2}$, Simone MUNdSTOCK JAHNKE¹ and Andreas KÖHLER ${ }^{2}$ \\ ${ }^{1}$ Laboratory of Biological Control of Insects, Faculty of Agronomy, Federal University of Rio Grande do Sul (UFRGS), \\ Avenida Bento Gonçalves, 7712, Porto Alegre, Rio Grande do Sul, Brazil; e-mail: cleder.pezzini@hotmail.com, \\ mundstock.jahnke@ufrgs.br \\ ${ }^{2}$ Laboratory of Entomology, Department of Life Sciences, University of Santa Cruz do Sul (UNISC), Avenida Independência, \\ 2293, Santa Cruz do Sul, Rio Grande do Sul, Brazil; e-mail: andreas@unisc.br
}

Key words. Hymenoptera, Braconidae, Habrobracon hebetor, Lepidoptera, Pyralidae, Ephestia kuehniella, biological control, ectoparasitoid, stored products, artificial diet, Nicotiana tabacum

\begin{abstract}
Host diet often influences its biological parameters and the success of their parasitoids, both in mass rearing, field research and parasitism in applied biological control programs. Habrobracon hebetor (Say, 1836) (Hymenoptera: Braconidae) is an important biological control agent of the flour moth Ephestia kuehniella (Zeller, 1879) (Lepidoptera: Pyralidae), which infests tobacco, grain and other products in storage. This study aimed to evaluate the effect of different proportions of tobacco in artificial diets on the biological parameters of the host $E$. kuehniella and its parasitoid $H$. hebetor. Four classes of Virginia tobacco with different sugar and nicotine concentrations were added to flour diets for moths in different percentages $(5,10$ and $15 \%)$. The experimental design was completely randomized in a $3 \times 4$ factorial scheme (percentage of dietary tobacco $\times$ class of tobacco). In the parasitoid bioassays, hosts fed only with $5 \%$ tobacco were used. For E. kuehniella, the development time (egg-adult), viability of immature stages, sex ratio, fecundity, egg viability and longevity were measured. For $H$. hebetor, percentage parasitism, offspring sex ratio, number of paralyzed and parasitized larvae, egg-adult viability and parasitism preference were measured. Tobacco classes and percentages added to the diet influenced the development time and viability of $E$. kuehniella. The $5 \%$ host diet did not influence the different biological parameters and behaviour of $H$. hebetor. For mass rearing of $H$. hebetor, it is unnecessary to add tobacco to the artificial diet in order to improve parasitoid performance.
\end{abstract}

\section{INTRODUCTION}

Integrated pest management programs using parasitoid wasps are becoming increasingly widespread because they are very effective at suppressing populations of agricultural insect pests (Heimpel \& Mills, 2017; Sampaio, 2018).

The rearing of parasitoids on a natural host is widely used and therefore, it is necessary to simultaneously improve the methods of rearing of their hosts and the mass production of high quality parasitoids (Parra, 2002, 2009). The food of the hosts is one of the main factors that can influence the quality of natural enemies produced in the laboratory. The diet must contain all the essential nutrients for the good development of the host and of high quality parasitoids (Vacari et al., 2012). Thus, these diets must be tested to verify the quality of both the hosts and natural enemies produced (Urrutia et al., 2007; Kishani Farahani et al., 2016).

Host quality is an essential factor in determining the fitness of the parasitoids. For the immature parasitoid the host is the sole source of nutrients (Urrutia et al., 2007). As a result, evaluation of host quality by the parental female parasitoid is critical to her reproductive success and offspring fitness, which results in a host selection trade-off between maximizing fecundity and selecting the most suitable hosts for the development of her offspring (Kishani Farahani et al., 2016). Studies indicate that host quality affects the adult size and reproductive performance (Harvey, 2005), female egg load at emergence, as well as sex allocation, percentage parasitism and immature developmental time of parasitoids (Kishani Farahani et al., 2016).

Quality of the food of the host affects not only the development or survival of parasitoids, but also their searching behaviour (Kazumu et al., 2019). The few studies on the foraging behaviour of parasitoids in a tritrophic context indicate that females prefer the odour of the food on which their host developed (Liu \& Jiang, 2003).

Habrobracon hebetor (Say, 1836) (Hymenoptera: Braconidae) is a larval ectoparasitoid, which parasitizes different 
species of moth such as Ephestia kuehniella (Zeller, 1879), Ephestia elutella (Hübner, 1796) and Plodia interpunctella (Hübner, 1813) (Lepidoptera: Pyralidae) (Ghimire \& Phillips, 2010, 2014; Farag et al., 2015; Lucas et al., 2015). These moths damage various stored products such as tobacco, flour and grain (Lorini et al., 2015; Athanassiou \& Arthur, 2018).

To use this parasitoid in biological control programs, mass rearing is necessary in order to obtain the large number of individuals required (Kehrli et al., 2005; Parra, 2009; Silva \& Brito, 2015; Solà et al., 2018). There are some reports of rearing $H$. hebetor on artificial diets in vitro (Magro \& Parra, 2002; Magro et al., 2006), however, mass rearing of this parasitoid on natural hosts is the most widely used (Aamer et al., 2015; Eslampour \& Aramideh, 2016). Therefore, the host is often raised on artificial diets that best support their development in the laboratory (Kurtuluş et al., 2020; Mohammadi \& Mehrkhou, 2020).

Although E. kuehniella attacks stored tabacco, it is usually reared on artificial diets mainly consisting of white or whole wheat flour and corn flour, with different percentages of yeast (Magrini et al., 1995; Solis et al., 2006; Ayvaz \& Karabörklü, 2008; Bhavanam, 2016; Vasconcelos, 2017). In general, based on the best development, nutritional quality, cost of production and ease of acquisition, the aforementioned authors recommend using a diet composed of whole wheat flour (97\%) and yeast (3\%) to E. kuehniella. Furthermore, the processes by which parasitoids find and recognize their hosts in the field can be influenced by the food used for rearing the host, which can adversely affect their effectiveness as biocontrol agents (McAuslane et al., 1990).

In Brazil, $H$. hebetor has already been evaluated for the control of Ephestia spp. (Parra, 2014) and according to this author (pers. commun.) this parasitoid is produced for controlling of E. elutella in stored tabacco. The tobacco plant provides a special challenge to parasitoids because of the presence of natural toxins and repellents (Ujváry, 1999), even so, $H$. hebetor has been found in surveys of tobacco warehouses. However, these parasitoids are adapted to the toxins in their environment (Brower et al., 1995). According to these authors, parasitoids from other cultures and those produced commercially are probably extremely sensitive to tobacco and must be selected for resistance over many generations in order for them to acquire tolerance. Therefore, commodities such as tobacco or hosts feeding on it may be toxic for strains of parasitoids that are not adapted to tobacco.

Although dry tobacco has an average of 0 to $20 \%$ sugar and 1 to $5 \%$ nicotine, these concentrations vary according to the variety, class, leaf position on the plant and its curing process, and is categorized into classes (Collins \& Hawks, 2011). The moths do not infest air-cured (Burley) and cigar types of tobacco or attack manufactured tobacco products. It prefers tobacco leaves with a high sugar and low nicotine content (Ashworth, 1993). However, the effect of a diet containing tobacco on the wasp has not been well studied. The hypothesis raised in this work is that, if tobacco is added to the diet when producing parasitoids for the biological control of E. kuehniella that infest stored tobacco, this may help females to recognize the host when released where the tobacco is stored. On the other hand, the addition of tobacco can compromise the development of hosts and parasitoids.

Thus, this study aimed to evaluate the effect of adding different percentages and classes of tobacco to the artificial diet used for rearing E. kuehniella on its biological parameters, such as the total development time, adult emergence, viability, sex ratio, number of oocytes per female, viability of the first eggs laid and adult longevity. In addition, the number of larvae paralyzed and parasitized, viability of egg to adult and sex ratio of its parasitoid, $H$. hebetor, as well as its preference for parasitizing hosts reared on different diets, were recorded.

\section{MATERIAL AND METHODS}

\section{Laboratory rearing}

Habrobracon hebetor and E. kuehniella were reared in the Entomology Laboratory at the Universidade de Santa Cruz do Sul (UNISC), in acclimatized rooms at a temperature of $28 \pm 2^{\circ} \mathrm{C}$, relative humidity (RH) of $50 \pm 20 \%$ and 14 -h photoperiod. The bioassays were conducted under the same environmental conditions. E. kuehniella was reared on an artificial diet consisting of wheat flour $(97 \%)$ and yeast (3\%) (Parra et al., 2014). The parasitoid was supplied with E. kuehniella larvae of last instar to parasitize.

\section{Bioassays with E. kuehniella}

Diets containing tobacco (Nicotiana tabacum var. Virginia) of four different classes with varying sugar and nicotine concentrations (Table 1) were tested. Each class of tobacco was added in percentages of 5,10 and $15 \%$ to the basic artificial diet (wheat flour + yeast).

Previously ground tobacco (in $3 \mathrm{~mm}$ ) was supplied by the JTI Company (Japan Tobacco International) and nicotine and sugar concentrations (glucose, maltose, sucrose, inositol, fructose) were measured using Near Infrared Ray equipment with electromagnetic waves from $80 \mathrm{~nm}$ to $2500 \mathrm{~nm}$.

The diets were prepared and stored in plastic containers $(12.2$ $\mathrm{cm}$ tall $\times 14.6 \mathrm{~cm}$ wide $\times 16.2 \mathrm{~cm}$ long) and covered with fine mesh fabric, which held $200 \mathrm{~g}$ of the food and $0.08 \mathrm{~g}$ of eggs (approximately 2,880 eggs). To evaluate the effect of the treatment on the biological parameters of E. kuehniella 20 replicates (containers) of each treatment were used. The experimental design was completely randomized in a $3 \times 4$ factorial scheme (percentage of tobacco in diet $\mathrm{X}$ class of tobacco). The artificial diet without tobacco was used as a control.

The development time (egg-adult), the viability of immature stage and the sex ratio of adults were measured from the moment the first adults emerged. Then, the number of individuals

Table 1. Sugar and nicotine concentrations in each class of Virginia tobacco.

\begin{tabular}{lcccc}
\hline \multirow{2}{*}{ Class } & $\begin{array}{c}\text { Leaf position } \\
\text { on the plant }\end{array}$ & $\begin{array}{l}\text { Indoor } \\
\text { class }\end{array}$ & \multicolumn{2}{c}{ Concentration (\%) } \\
\cline { 3 - 5 } & B (leaf) & B2LF & Sugar & Nicotine \\
\hline Tobacco 1 & C (cutters) & C2LS & 17.60 & 3.51 \\
Tobacco 2 & B (leaf) & B2MF & 6.39 & 1.58 \\
Tobacco 3 & C (cutters) & C4BS & 4.57 & 1.07 \\
\hline
\end{tabular}

* Classification followed by JTI Company (leaf position on the plant, quality, colour, style). 
that emerged was recorded every $48 \mathrm{~h}$, until no more emerged for two weeks. The classification of the sexes was done by observing the external reproductive organs under a stereomicroscope.

After emergence, 20 couples of 24-h old E. kuehniella were separated, which consisted of the first individuals that emerged in each treatment. Each couple was placed in a plastic bottle (5.0 $\mathrm{cm}$ diameter and $6.5 \mathrm{~cm}$ height) with no food and the longevity of the males and females recorded. The fecundity of E. kuehniella was obtained by counting the number of oocytes in $20<24$-h old paired females, which again consisted of the first to emerge in each treatment. Females were killed using ethyl acetate vapour and dissected in ethanol (70\%) under a stereomicroscope.

Adults of E. kuehniella from each treatment were placed in oviposition cages for $24 \mathrm{~h}$ to record the viability of the first eggs laid. Afterwards, 1,000 eggs were separated and observed for 48 $\mathrm{h}$ to determine the percentage that hatched. The sex ratio of the next generation (F2) was obtained by placing the eggs from each treatment in a container with the same diet as that used to rear the adult E. kuehniella. There were twenty replicates of each treatment ( $0.08 \mathrm{~g}$ of eggs in $200 \mathrm{~g}$ of diet) in which the sex of all the adults that emerged were recorded.

\section{Bioassays of $\boldsymbol{H}$. hebetor}

Last instar larvae of E. kuehniella reared on diets each containing $5 \%$ of one of the four classes of tobacco used in the previous bioassays (Table 1) were used to test parasitism by H. hebetor, which emerged from hosts raised on an artificial diet without tobacco. This percentage was chosen, since in previous bioassays it was recorded that E. kuehniella did not develop on diets with a higher percentage of tobacco.

To evaluate the numbers of larvae paralyzed and parasitized, viability and sex ratio of $H$. hebetor, females from different original hosts (these hosts reared on different diets) received offered hosts also reared on the four types of diets or in the control (Table 2).

Mortality of the developmental stages of $H$. hebetor in each of the treatments was determined as described above by evaluating the responses of 10 E. kuehniella larvae exposed to a parasitoid couple for $24 \mathrm{~h}$ in Petri dishes ( $9 \mathrm{~cm}$ diameter by $2 \mathrm{~cm}$ height). Afterwards, the parasitoids were removed from the plates and the number of larvae paralyzed and parasitized, and the number of eggs on the larvae were recorded. Paralyzed larvae were those that did not move when stimulated and parasitized larvae were those that had parasitoid eggs on their body. To record the number of living individuals at each stage of development, the reproductive success and sex ratio, the progeny were kept under the same

Table 2. Treatments evaluated according to the larvae diet (Ephestia kuehniella) of the original host of Habrobracon hebetor females and the larvae offered to parasitism.

\begin{tabular}{cc}
\hline \multicolumn{1}{c}{ E. kuehniella diet } \\
\hline Original host & \multicolumn{1}{c}{ Offered host } \\
\hline Wheat flour & Wheat flour \\
& Wheat flour with tobacco 1 \\
& Wheat flour with tobacco 2 \\
& Wheat flour with tobacco 3 4 \\
Wheat flour with tobacco 1 & Wheat flour with tobacco 1 \\
Wheat flour with tobacco 2 & Wheat flour with tobacco 2 \\
Wheat flour with tobacco 3 & Wheat flour with tobacco 3 \\
Wheat flour with tobacco 4 & Wheat flour with tobacco 4
\end{tabular}

Tobacco diets contained $5 \%$ of tobacco in addition to the other constituents. Tobacco 1: sugar $20.37 \%$, nicotine $3.51 \%$. Tobacco 2 : sugar $17.60 \%$, nicotine $1.58 \%$. Tobacco 3 : sugar $6.39 \%$, nicotine $3.97 \%$. Tobacco 4: sugar $4.57 \%$, nicotine $1.07 \%$.

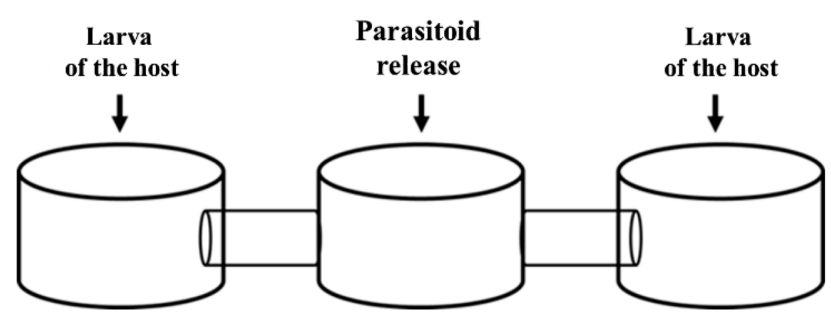

Fig. 1. Schematic diagram of the double choice arena for determining parasitism preferences of Habrobracon hebetor.

conditions. After three days, the host larvae were inspected and the number of last instar larvae of the parasitoid recorded, after nine days the number of pupae and after 12 days the number of adults. There were twenty replicates of each treatment, with a completely randomized design.

\section{Host preference of $\boldsymbol{H}$. hebetor}

The preference of $H$. hebetor females for different hosts was evaluated by comparing the origin of the parasitoid in which hosts that were fed the basic artificial diet (white wheat flour + yeast) and those fed a diet containing $5 \%$ of tobacco 2 . The $E$. kuehniella larvae offered for parasitism were reared on the same two diets.

A double-choice parasitism arena was built with a $7 \mathrm{~cm} \times 5$ $\mathrm{cm}$ container in the centre to which at opposite ends equal sized containers were connected by means of a $1 \mathrm{~cm} \times 5 \mathrm{~cm}$ pipe (Fig. 1). The containers at each end of the arena contained 10 larvae of E. kuehniella with no food. A previously paired $H$. hebetor female $(<24 \mathrm{~h}$ old $)$, without experience of parasitism, was released in the central container of the arena.

The first choice of each parasitoid for one of the outer containers was recorded and after $24 \mathrm{~h}$ of exposure the number of larvae paralyzed and parasitized in each container and the number of eggs on them were counted. There were 40 replicates of each treatment.

\section{Data analysis}

The data were averaged and analysed for normality using the Shapiro-Wilk test, homoscedasticity using the Hartley test and independence of residues using graphic analysis.

For the different biological parameters evaluated for E. kuehniella and H. hebetor, ANOVA assumptions were met, therefore, the parametric student t-test was used for two samples and Tukey for more than two samples $(\mathrm{p}<0.05)$. The sex ratio, viability and percentage preference for parasitism were compared using the $\chi^{2}$ heterogeneity test $(\mathrm{p}<0.05)$ (Ayres et al., 2007).

\section{RESULTS}

\section{Biological aspects of E. kuehniella}

Within one generation, the total development time of $E$. kuehniella was influenced by the class and percentage of tobacco added to the diet (Table 3 ). The duration of egg-adult period on diets containing tobacco 1 and 3 was significantly longer than on those containing the same percentages of tobacco 2 and 4 . In addition, there was a significant increase in development time with increase in the percentage of tobacco 1 and 3 in the diet (Table 3). Ephestia kuehniella did not develop when the diet contained $15 \%$ of tobacco 1 and 3. The average development time of insects reared on diets containing $5 \%$ of tobacco 2 and 4 did not differ from that of the control (wheat flour only). For other percentages, the development time was longer for these classes of 
Table 3. Biological data (mean \pm standard deviation) of Ephestia kuehniella reared in the different treatments and tobacco percentage at $28 \pm 2{ }^{\circ} \mathrm{C}, 50 \pm 20 \% \mathrm{RH}$ and 14 -h photoperiod: Control: wheat flour diet. Tobacco 1 : sugar $20.37 \%$, nicotine $3.51 \%$. Tobacco 2 : sugar $17.60 \%$, nicotine $1.58 \%$. Tobacco 3: sugar 6.39\%, nicotine 3.97\%. Tobacco 4: sugar 4.57\%, nicotine $1.07 \%$.

\begin{tabular}{|c|c|c|c|c|c|}
\hline \multicolumn{2}{|c|}{ Treatment/Percentage of tobacco in diet } & \multirow{2}{*}{$\frac{\text { Developmental time (days) }}{39.8 \pm 1.10 \mathrm{a}}$} & \multirow{2}{*}{$\begin{array}{c}\text { Number of adults that emerged } \\
939.0 \pm 91.33 \mathrm{a}\end{array}$} & \multirow{2}{*}{$\frac{\text { Viability (\%) }}{32.6}$} & \multirow{2}{*}{$\frac{\text { Sex ratio* }^{*}}{0.50}$} \\
\hline Control & & & & & \\
\hline & $5 \%$ & $48.2 \pm 1.10 \mathrm{c}$ & $443.2 \pm 59.86 \mathrm{~d}$ & 15.4 & 0.55 \\
\hline \multirow[t]{3}{*}{ Tobacco 1} & $10 \%$ & $65.4 \pm 4.22 \mathrm{e}$ & $33.2 \pm 16.61 \mathrm{f}$ & 1.2 & 0.57 \\
\hline & $15 \%$ & - & - & - & - \\
\hline & $5 \%$ & $42.2 \pm 1.10 a b$ & $858.8 \pm 18.02 a b$ & 29.8 & 0.51 \\
\hline \multirow[t]{3}{*}{ Tobacco 2} & $10 \%$ & $47.8 \pm 1.10 b c$ & $783.4 \pm 52.45 b$ & 27.2 & 0.52 \\
\hline & $15 \%$ & $57.8 \pm 1.80 \mathrm{~d}$ & $321.8 \pm 62.15 \mathrm{e}$ & 11.1 & 0.55 \\
\hline & $5 \%$ & $49.4 \pm 1.67 c$ & $360.2 \pm 29.56 \mathrm{de}$ & 12.5 & 0.54 \\
\hline \multirow[t]{3}{*}{ Tobacco 3} & $10 \%$ & $77.4 \pm 8.66 \mathrm{f}$ & $5.4 \pm 5.85 \mathrm{f}$ & 0.2 & 0.56 \\
\hline & $15 \%$ & - & - & - & - \\
\hline & $5 \%$ & $42.2 \pm 1.10 a b$ & $860.2 \pm 53.04 a b$ & 29.8 & 0.49 \\
\hline \multirow[t]{2}{*}{ Tobacco 4} & $10 \%$ & $45.8 \pm 1.10 b c$ & $811.2 \pm 32.32$ b & 28.1 & 0.50 \\
\hline & $15 \%$ & $55.0 \pm 1.41 d$ & $547.0 \pm 32.21 \mathrm{c}$ & 18.9 & 0.53 \\
\hline
\end{tabular}

- No adults emerged. Different lower case letters in a column indicate significant differences based on a Tukey test ( $p<0.05)$. ${ }^{*}$ No significant difference based on $x^{2}$ heterogeneity test $(p>0.05)$.

tobacco, however, development was also recorded on diets containing 15\% (Table 3).

The average numbers of adults of E. kuehniella that emerged from the control and 5\% tobacco 2 and 4 treatments was similar, with significantly lower averages for the other treatments (Table 3). Viability (\%) of E. kuehniella decreased as more tobacco was added to the diet, regardless of the class of tobacco tested (Table 3). In the first generation the sex ratio did not differ significantly between any of the treatments (Table 3). Similarly, no change in the sex ratio of the F2 generation was recorded for any treatment, which ranged from 0.59 to $0.43\left(\chi^{2}=4.518 ; \mathrm{gl}=10\right.$; $\mathrm{p}<0.05)$.

The number of oocytes per female did not differ between females reared on the different diets, which ranged from $182.7 \pm 37.05$ to $208.4 \pm 41.40$ (Table 4). Despite the emergence of adults from treatments with class 1 and 3 tobacco $(10 \%)$, it was not possible to evaluate the number of oocytes per female, viability of first oviposition eggs or longevity of adults due to the low number of individuals due to the viability being below $1.2 \%$ (Table 3,4 ). The viability of the eggs from individuals that were reared on artificial diets with different classes and percentages of tobacco was above $97 \%$ for all treatments (Table 4). Similarly, the average longevity of females and males did not differ significantly from the control in any of the treatments. On average, males lived longer than females, regardless of treatment (Table 4).

The average daily emergency curves showed that for $E$. kuehniella more than $95 \%$ of the individuals on the control diet and tobacco classes 2 and 4 to $5 \%$ have already emerged after one month (Fig. 2). However, from treatments with the same percentage of class 1 and 3 tobacco less than 58\% emerged (Fig. 2). In the same period, the cumulative emergence from the treatments with $10 \%$ of class 2 and 4 tobacco was $54 \%$ and $75 \%$, respectively, and for class 1 and 3 tobacco, 9\% and 3\% (Fig. 2). Only 12\% and $24 \%$ had emerged within four-weeks from the treatments with $15 \%$ class 2 and 4 tobacco (Fig. 2).

Table 4. Reproductive parameters and adult longevity (mean \pm standard deviation) of Ephestia kuehniella under conditions of $28 \pm 2{ }^{\circ} \mathrm{C}, 50$ $\pm 20 \% \mathrm{RH}$ and 14-h photoperiod, recorded in the different treatments. Control: wheat flour diet. Tobacco 1: sugar $20.37 \%$, nicotine $3.51 \%$. Tobacco 2: sugar $17.60 \%$, nicotine 1.58\%. Tobacco 3: sugar 6.39\%, nicotine 3.97\%. Tobacco 4: sugar $4.57 \%$, nicotine $1.07 \%$.

\begin{tabular}{|c|c|c|c|c|c|}
\hline \multirow{2}{*}{\multicolumn{2}{|c|}{$\begin{array}{l}\text { Treatment / Percentage of tobacco } \\
\text { in diet }\end{array}$}} & \multirow{2}{*}{$\begin{array}{c}\text { Number of oocytes } \\
\text { per female* }\end{array}$} & \multirow{2}{*}{$\begin{array}{l}\text { Viability of first } \\
\text { eggs laid }(\%)^{\star *}\end{array}$} & \multicolumn{2}{|c|}{ Adult longevity (days) } \\
\hline & & & & $\sigma^{*}$ & $q^{*}$ \\
\hline \multirow[t]{2}{*}{ Control } & & $204.2 \pm 50.71$ & 98.1 & $10.8 \pm 2.93 a$ & $7.3 \pm 1.88 b$ \\
\hline & $5 \%$ & $192.2 \pm 33.38$ & 97.7 & $11.1 \pm 1.17 \mathrm{a}$ & $7.5 \pm 1.99 b$ \\
\hline \multirow[t]{2}{*}{ Tobacco 1} & $10 \%$ & - & - & - & - \\
\hline & $15 \%$ & - & - & - & - \\
\hline \multirow{3}{*}{ Tobacco 2} & $5 \%$ & $202.8 \pm 37.31$ & 98.6 & $10.9 \pm 1.07 a$ & $7.3 \pm 1.86 b$ \\
\hline & $10 \%$ & $208.4 \pm 41.40$ & 98.7 & $10.4 \pm 1.13 a$ & $7.2 \pm 1.52 b$ \\
\hline & $15 \%$ & $187.3 \pm 34.88$ & 97.5 & $10.3 \pm 1.37 \mathrm{a}$ & $7.7 \pm 1.51 b$ \\
\hline \multirow{2}{*}{ Tobacco 3} & $5 \%$ & $188.8 \pm 43.61$ & 98.1 & $11.3 \pm 1.26 \mathrm{a}$ & $8.3 \pm 2.21 b$ \\
\hline & $10 \%$ & - & - & - & - \\
\hline \multirow{4}{*}{ Tobacco 4} & $15 \%$ & - & - & - & - \\
\hline & $5 \%$ & $182.7 \pm 37.05$ & 98.8 & $10.5 \pm 1.69 a$ & $7.6 \pm 1.80 \mathrm{~b}$ \\
\hline & $10 \%$ & $207.9 \pm 29.17$ & 97.9 & $10.6 \pm 1.60 a$ & $6.9 \pm 1.87 b$ \\
\hline & $15 \%$ & $196.2 \pm 43.46$ & 98.9 & $10.8 \pm 1.47 \mathrm{a}$ & $7.9 \pm 2.04 b$ \\
\hline
\end{tabular}

- No emergence of adults or insufficient for evaluation. * No significant difference based on Tukey test ( $p>0.05)$. ${ }^{* *}$ No significant difference based on $x^{2}$ heterogeneity test $(p>0.05)$. Different lower case letters in a line indicate significant differences based on test $(p<$ 0.05). 

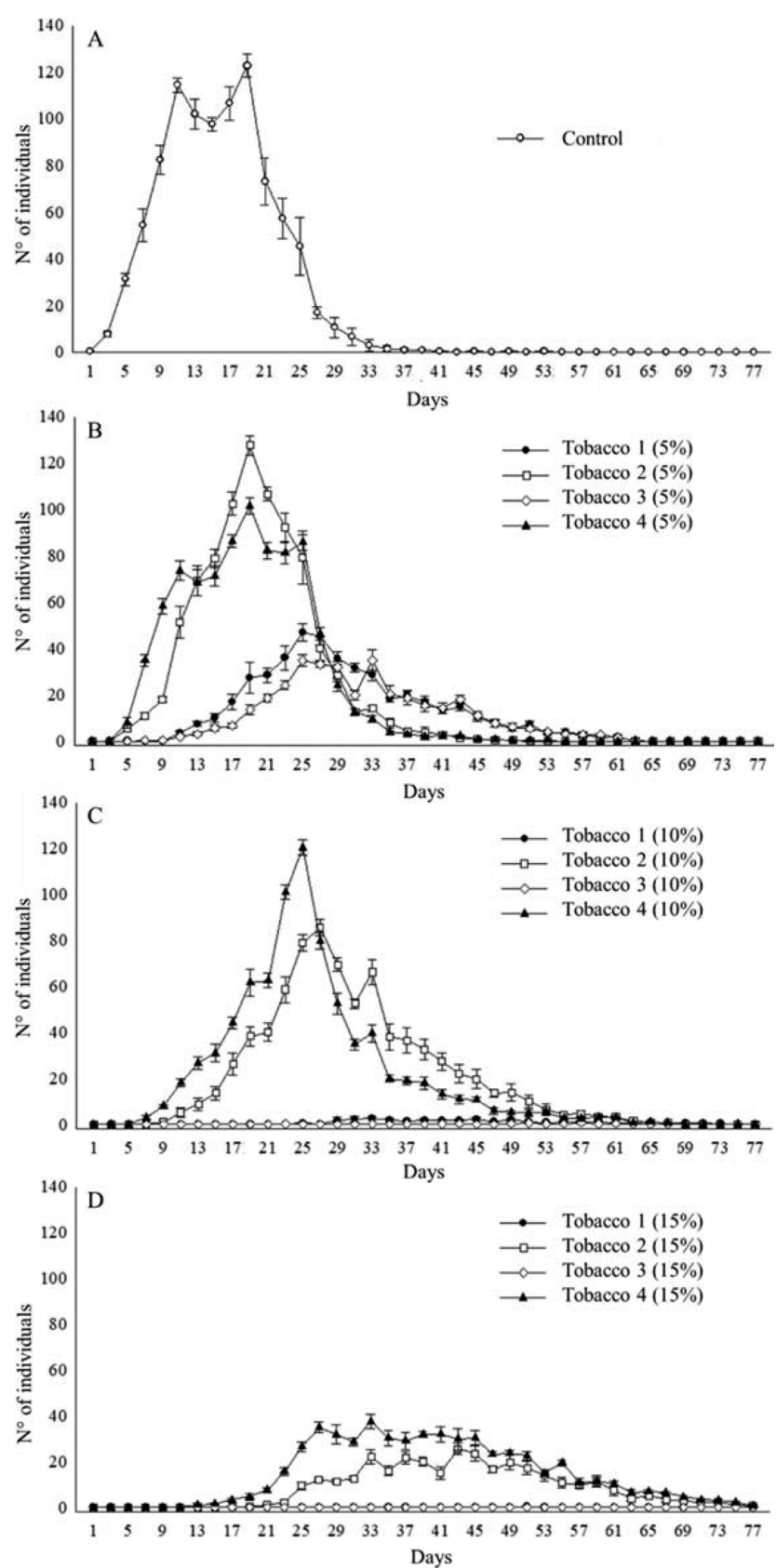

Fig. 2. Average number ( \pm standard error) of adult Ephestia kuehniella that emerged over time in the different treatments. A - control, B - 5\% tobacco added to the diet, C - 10\%, D - 15\%. Control: wheat flour diet. Tobacco 1: sugar $20.37 \%$, nicotine $3.51 \%$. Tobacco 2: sugar $17.60 \%$, nicotine $1.58 \%$. Tobacco 3 : sugar $6.39 \%$, nicotine $3.97 \%$. Tobacco 4 : sugar $4.57 \%$, nicotine: $1.07 \%$.

\section{Biological aspects and behaviour of $\boldsymbol{H}$. hebetor}

The diets of the original host of the parasitoid females and of those larvae that they parasitized, did not influence the ability of $H$. hebetor to paralyze and parasite (Table 5). Within each treatment, the average number of larvae paralyzed per female was always higher than that parasitized, with no difference between treatments for both parameters (Table 5).

In terms of fecundity, the average number of eggs laid by $H$. hebetor in $24 \mathrm{~h}$ was also not affected by the diet of their original hosts or of the larvae they parasitized (Table

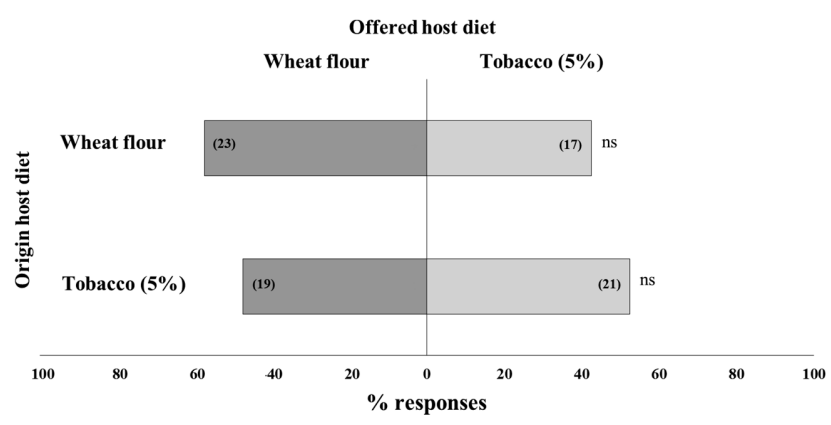

Fig. 3. Percentage of females of Habrobracon hebetor that emerged from larvae reared on either a diet of wheat flour or the same diet to which $5 \%$ tobacco added, which responded to simultaneously exposed larvae of Ephestia kuehniella fed on the above two diets, under conditions of $28 \pm 2^{\circ} \mathrm{C}, 50 \pm 20 \% \mathrm{RH}$ 14-h photoperiod. Values in parentheses indicate the number of responses to each parasitism unit. (ns - no significant difference based on the $X^{2}$ heterogeneity test, $p>0.05$ ).

6). The overall viability of the immature stages of $H$. hebetor did not vary between treatments and was between $34.92 \%$ and $45.03 \%$. Comparison of the effect of the diet of their original hosts and that of the larvae they parasitized revealed no significant differences in the sex ratio, which on average was $0.69\left(\chi^{2}=0.368 ; \mathrm{gl}=8 ; \mathrm{p}>0.05\right)$ (Table 6).

\section{Parasitism preference}

Females of $H$. hebetor that emerged from hosts fed only on wheat flour or this diet with $5 \%$ tobacco showed no preference for larvae reared on either of these diets (Fig. 3). When offered a choice between the two parasitism units the parasitoid did not change its response and remained in a unit for up to $24 \mathrm{~h}$.

The average numbers of larvae paralyzed and parasitized, and eggs laid in each unit by the parasitoid did not differ between treatments (Table 7). All the larvae of $E$. kuehniella in the unit not visited by the parasitoid survived.

\section{DISCUSSION}

The increased developmental time of E. kuehniella reared on diets containing tobacco with high levels of nicotine (Table 3) could indicate a lower nutritional quality or the presence of unsuitable substances in these diets. According to Parra et al. (2014) the average egg-adult time on a diet consisting of wheat flour $(97 \%)$ and yeast $(3 \%)$, at a temperature of $28^{\circ} \mathrm{C}$, is 41 days, which corresponds to that recorded on the control diet in the present study. On some of the diets used in this study the average development times were 77 days, nearly twice the normal developmental period. In addition, E. kuehniella did not complete its development on diets with high percentages of some classes of tobacco. This may be due to the presence of toxic substances such as pyrimidine alkaloids like nicotine and anabasine, as well as the steroids, coumarins and terpenes that are in tobacco and are used as insecticides in agriculture and a vermifuge in livestock because of the high concentrations of these compounds, especially nicotine, in class 1 and 3 tobacco (Moratore et al., 2009; Jacomini et al., 2016). 
Table 5. Number of larvae of Ephestia kuehniella paralyzed and parasitized (mean \pm standard deviation) by Habrobracon hebetor in the different treatments, under conditions of $28 \pm 2{ }^{\circ} \mathrm{C}, 50 \pm 20 \% \mathrm{RH}$ and 14-h photoperiod.

\begin{tabular}{|c|c|c|c|}
\hline \multicolumn{2}{|c|}{ E. kuehniella diet } & \multirow{2}{*}{$\begin{array}{c}\text { Number of paralyzed } \\
\text { larvae * }\end{array}$} & \multirow{2}{*}{$\begin{array}{c}\text { Number of parasitized } \\
\text { larvae * }\end{array}$} \\
\hline Original host & Offered host & & \\
\hline \multirow{5}{*}{ Wheat flour } & Wheat flour & $8.5 \pm 1.98 a$ & $3.9 \pm 1.57 b$ \\
\hline & Wheat flour with tobacco 1 & $8.0 \pm 1.20 \mathrm{a}$ & $4.2 \pm 1.19 b$ \\
\hline & Wheat flour with tobacco 2 & $8.8 \pm 1.30 a$ & $3.6 \pm 1.31 b$ \\
\hline & Wheat flour with tobacco 3 & $9.1 \pm 0.96 a$ & $4.4 \pm 1.47 b$ \\
\hline & Wheat flour with tobacco 4 & $8.6 \pm 1.14 a$ & $3.6 \pm 1.14 b$ \\
\hline Wheat flour with tobacco 1 & Wheat flour with tobacco 1 & $7.9 \pm 1.40 \mathrm{a}$ & $4.7 \pm 1.11 b$ \\
\hline Wheat flour with tobacco 2 & Wheat flour with tobacco 2 & $9.1 \pm 0.81 a$ & $3.9 \pm 1.33 b$ \\
\hline Wheat flour with tobacco 3 & Wheat flour with tobacco 3 & $8.4 \pm 1.19 a$ & $4.2 \pm 1.15 b$ \\
\hline Wheat flour with tobacco 4 & Wheat flour with tobacco 4 & $9.0 \pm 1.41 \mathrm{a}$ & $3.6 \pm 1.23 b$ \\
\hline
\end{tabular}

Tobacco diets contained $5 \%$ of tobacco in addition to the other constituents. Tobacco 1: sugar $20.37 \%$, nicotine $3.51 \%$. Tobacco 2 : sugar $17.60 \%$, nicotine $1.58 \%$. Tobacco 3: sugar $6.39 \%$, nicotine $3.97 \%$. Tobacco 4 : sugar $4.57 \%$, nicotine $1.07 \%$. Different lower case letters on a line indicate a significant difference based on t test $(p<0.05)$. ${ }^{*}$ No significant difference based on Tukey test $(p>0.05)$.

Table 6. Survival of Habrobracon hebetor (mean \pm standard deviation) in the larvae of Ephestia kuehniella in the different treatments, under conditions of $28 \pm 2^{\circ} \mathrm{C}, 50 \pm 20 \% \mathrm{RH}$ and 14-h photoperiod.

\begin{tabular}{|c|c|c|c|c|c|c|c|}
\hline \multicolumn{2}{|c|}{ E. kuehniella diet } & \multicolumn{4}{|c|}{ Number } & \multirow{2}{*}{$\begin{array}{c}\text { Viability } \\
\text { egg-adult (\%) }\end{array}$} & \multirow{2}{*}{ Sex ratio** } \\
\hline Original host & Offered host & Eggs* & Larvae $^{*}$ & Pupae* & Adults* & & \\
\hline \multirow{5}{*}{ Wheat flour } & Wheat flour & $19.1 \pm 3.81$ & $9.9 \pm 4.39$ & $8.8 \pm 4.22$ & $8.6 \pm 4.22$ & 45.1 & 0.68 \\
\hline & Wheat flour with tobacco 1 & $17.9 \pm 3.99$ & $6.9 \pm 4.67$ & $6.2 \pm 3.93$ & $6.1 \pm 4.32$ & 34.2 & 0.62 \\
\hline & Wheat flour with tobacco 2 & $18.1 \pm 7.92$ & $9.7 \pm 8.84$ & $8.4 \pm 7.48$ & $8.1 \pm 7.21$ & 44.6 & 0.69 \\
\hline & Wheat flour with tobacco 3 & $18.5 \pm 5.33$ & $9.3 \pm 3.86$ & $8.8 \pm 4.81$ & $8.2 \pm 4.14$ & 44.6 & 0.70 \\
\hline & Wheat flour with tobacco 4 & $17.9 \pm 6.06$ & $7.4 \pm 3.67$ & $6.6 \pm 3.79$ & $6.2 \pm 3.30$ & 34.9 & 0.72 \\
\hline Wheat flour v & Wheat flour with tobacco 1 & $18.5 \pm 3.64$ & $9.0 \pm 5.33$ & $8.2 \pm 4.59$ & $8.1 \pm 4.17$ & 43.5 & 0.65 \\
\hline Wheat flour with tobacco 2 & Wheat flour with tobacco 2 & $17.1 \pm 3.94$ & $7.7 \pm 4.30$ & $7.1 \pm 4.48$ & $6.9 \pm 4.45$ & 40.7 & 0.70 \\
\hline Wheat flour with tobacco 3 & Wheat flour with tobacco 3 & $18.1 \pm 2.96$ & $8.9 \pm 3.30$ & $8.1 \pm 3.85$ & $7.9 \pm 3.62$ & 43.7 & 0.71 \\
\hline Wheat flour with tobacco 4 & Wheat flour with tobacco 4 & $17.9 \pm 6.06$ & $7.4 \pm 3.67$ & $6.6 \pm 3.79$ & $6.2 \pm 3.30$ & 34.9 & 0.72 \\
\hline
\end{tabular}

Tobacco diets contained $5 \%$ of tobacco in addition to the other constituents. Tobacco 1 : sugar $20.37 \%$, nicotine $3.51 \%$. Tobacco 2 : sugar $17.60 \%$, nicotine $1.58 \%$. Tobacco 3: sugar $6.39 \%$, nicotine $3.97 \%$. Tobacco 4 : sugar $4.57 \%$, nicotine $1.07 \%$. ${ }^{*}$ No significant difference based on Tukey test $(p>0.05)$. ${ }^{* *}$ No significant difference based on $x^{2}$ heterogeneity test $(p>0.05)$.

In the present study the diets with more than $5 \%$ of tobacco adversely affected the immature stages of E. kuehniella, resulting in fewer adults emerging, especially from treatments with the classes of tobacco with high concentrations of nicotine. This result can be expected, since tobacco contains substances that are toxic for insects, especially nicotine (Ujváry, 1999). Even so, this species is cited as a pest of stored Virginia tobacco (Gallo et al., 2002; Guedes \& Costa, 2006) although farmers report that the Burley variety is attacked less (Krsteska, 2014).

On the other hand, the viability of E. kuehniella was low in all the treatments and similar results are reported for

Table 7. Mean numbers ( \pm standard deviation) of larvae of $E$. kuehniella that were reared in the different treatments that were paralyzed and parasitized and of the eggs laid on them by females of Habrobracon hebetor, under conditions of $28 \pm 2^{\circ} \mathrm{C}, 50 \pm 20 \% \mathrm{RH}$ and 14-h photoperiod.

\begin{tabular}{|c|c|c|c|c|}
\hline \multicolumn{2}{|c|}{ E. kuehniella diet } & \multirow{2}{*}{$\begin{array}{c}\text { Number of } \\
\text { paralyzed } \\
\text { larvae* }\end{array}$} & \multirow{2}{*}{$\begin{array}{c}\text { Number of } \\
\text { parasitized } \\
\text { larvae }\end{array}$} & \multirow{2}{*}{$\begin{array}{l}\text { Number } \\
\text { of eggs* }\end{array}$} \\
\hline Original host & Offered host & & & \\
\hline \multirow[b]{2}{*}{ Wheat flour } & $\mathrm{Wh}$ & $6.5 \pm 1.27$ & $3.4 \pm 1.19$ & 24 \\
\hline & $\begin{array}{c}\text { Wheat flour with } \\
\text { tobacco }(5 \%)\end{array}$ & $7.3 \pm 1.28$ & $3.7 \pm 1.38$ & 15 \\
\hline \multirow{2}{*}{$\begin{array}{c}\text { Wheat flour } \\
\text { with tobacco } \\
(5 \%)\end{array}$} & Wh & $6.9=$ & $2.8 \pm 1.02$ & 13.5 \\
\hline & $\begin{array}{l}\text { Wheat flour with } \\
\text { tobacco }(5 \%)\end{array}$ & \pm 1.51 & $2.9 \pm 0.99$ & 5.94 \\
\hline
\end{tabular}

\footnotetext{
* No significant differences based on Tukey test $(p>0.05)$
}

different artificial diets (Magrini et al., 1995; Solis et al., 2006; Vasconcelos, 2017). Reasons for the wide variation in viability during the egg-adult period may be the genotype or origin of the products used to formulate the artificial diets, since the methodology used in the different studies are similar. As reported for other insects, another factor that could be important is adaptation that occurs due to the accumulation of characteristics in a population reared over several generations in the laboratory, which can lead to speciation (Souza, 2016).

Diets on which individuals developed did not affect the sex ratio of the offspring. The desirable sex ratio for rearing E. kuehniella is close to 0.5 (Bhavanam, 2016; Vasconcelos, 2017) and the values recorded in our study are similar to this. This is important as it indicates good insect breeding as there are a relatively high number of females, when the sex ratio is close to or higher than 0.5 (Magrini et al., 1993; Ayvaz \& Karabörklü, 2008), which ensures a large number of eggs for maintenance of their rearing and of parasitoids' rearing.

Another biological parameter evaluated was the number of oocytes per newly emerged female, which did not differ between treatments. It is important to remember that no other studies were found evaluating this parameter for $E$. kuehniella, however, as the number of oocytes reflects oviposition, it is possible to compare our results with those of 
Vasconcelos (2017), which evaluate different rearing diets and report no variation in the number of eggs, which possibly indicates that there is also no variation in the number of oocytes in females. The classes and percentages of tobacco added to the diets did not affect egg viability, which is also reported by Coelho Filho (2010), Coelho Filho \& Parra (2013), Bhavanam (2016) and Vasconcelos (2017), who registered an egg viability of over $90 \%$ for this species.

No differences were recorded in the longevity of females of E. kuehniella between the treatments, which indicates that tobacco in the diets does not affect this parameter. Longevity records for females are 6 to 8 days (Stein \& Parra, 1987; Ayvaz \& Karabörklü, 2008; Vasconcelos, 2017) and are more dependent on temperature, being longer at low than at high temperatures (Coelho Filho, 2010), than on the composition of the diet. The males of E. kuehniella lived longer than the females in all treatments, as they died as soon as they stopped ovipositing, which is also reported by Ayvaz \& Karabörklü (2008), Coelho Filho (2010) and Vasconcelos (2017).

The daily percentage emergence of E. kuehniella was highest in the control up to the fourth week, during which more than $95 \%$ of the adults emerged. Similar results are reported by Magrini et al. (1995), who report that more than $97 \%$ of the adults emerged until the fourth week when reared on a diet of white and yellow corn. The same was recorded here for diets with a 5\% content of class 1 and 2 tobacco. In the other treatments, time to emergence was longer and the number of adults that emerged was lower.

Our results indicate that host diets containing $5 \%$ of the different classes of tobacco had no significant effect on a wide range of characteristics related to the rearing of $H$. hebetor, including paralyzing ability, parasitism, fertility, fecundity, viability and sex ratio. These variables have important implications for the population dynamics of the parasitoid. Although the study of Vacari et al. (2012) indicates that host diet may influence the performance of parasitoids, such as Cotesia flavipes (Cameron, 1891) (Hymenoptera: Braconidae), the same was not recorded in the present study. Other studies on the same aspects, such as those of Urrutia et al. (2007) and Faal-Mohammad-Ali \& Shishehbor (2013), also did not record clear differences in parasitoid fitness associated with differences in the diet of the host.

Higher numbers of larvae were paralyzed than parasitized in all treatments, which indicates that females tend to paralyze many more hosts than they parasitize. Ghimire \& Phillips (2014) report that $H$. hebetor females try to paralyze all nearby hosts before ovipositing. According to Soliman (1940) and Hagstrum (1983), the number of larvae that a female of $H$. hebetor can paralyze within $24 \mathrm{~h}$ depends mainly on the age of the parasitoid and the density of hosts.

As mentioned in other studies, paralyzed larvae are used by females as a source of food as they feed on the haemolymph, which exudes from the body of the host where the parasitoid inserted its ovipositor in order to paralyse it (Hagstrum, 1983; Serra, 1992). As no differences in this behaviour was recorded in the present study, it seems reasonable to assume that diet did not influence the nutritional quality of the host larvae.

In our study, the sex ratio of $H$. hebetor parasitizing $E$. kuehniella was not altered by the different treatments. In contrast, when $H$. hebetor parasitized Corcyra cephalonica (Stainton, 1865) (Lepidoptera: Pyralidae) the host diet influenced the production of more females, with the wheat diet being the most suitable (Singh et al., 2006). Our study corroborates the results of Faal-Mohammad-Ali \& Shishehbor (2013), who report that the proportion of $H$. hebetor that are females and their fecundity is not affected by whether the diet of their host is wheat flour or corn, rice and barley. The above indicates that host species could possibly have a greater influence on these biological parameters than the diets of the larvae they parasitized. Although no differences were recorded in the progeny and sex ratio of $H$. hebetor, it is important to remember that qualitative and quantitative differences in the chemical composition and physical characteristics of the diets of the host may affect the biological parameters that influence population growth (Singh et al., 2006).

As the overall viability of the immature stages of $H$. hebetor was not altered by the diet of the original host or by the diet of the larvae offered to parasitism, it is inferred that the $5 \%$ of the different clases of tobacco added to diet did not affect its biology. However, the diet of hosts could affect the searching behaviour and parasitism by the parasitoid in the field as is reported by McAuslane et al. (1990), who report changes in the interaction between parasitoids and their hosts.

The females of $H$. hebetor used in this study showed no preference for parasitizing larvae of E. kuehniella depending on whether they were reared on diets with or without $5 \%$ tobacco and their preference was also not dependent on the diet of their original host. These results accord from those of Souza et al. (2014) who report that larvae of Diatraea saccharalis (Fabricius, 1794) (Lepidoptera: Crambidae) fed on different varieties of their host plant were equally preferred by female $C$. flavipes. Parasitism preference seems to be more associated with the original host species than its diet (Tognon et al., 2014). This is demonstrated by Goulart et al. (2011), who report that the parasitoid $T$. pretiosum parasitizes eggs of different species, but prefers those of E. kuehniella. There is little evidence that parasitoids prefer to parasitize hosts that have fed on a particular food (Vacari et al., 2012).

According to Darwish et al. (2003) and Akinkurolere et al. (2009), several host stimuli affect the searching behaviour of the parasitoid $H$. hebetor, in particular, the mandibular gland secretions produced by larvae when feeding, as well as their faeces and secretions. The odours released by the host stimulate the parasitoid to start probing. Furthermore, Darwish et al. (2013) highlight that H. hebetor females respond to kairomone released by host larvae, which intensifies their searching and oviposition behaviour. Furthermore, based on olfactometry tests, the volatiles emitted by the faeces of E. kuehniella larvae, known as frass, help 
attract $H$. hebetor females (Favaris, 2016). However. host larvae fed diets with or without tobacco do not change this behaviour in the parasitoid, which is attracted to the host in the same way.

As there were no changes in the biological parameters studied and no increase in preference for parasitizing particular hosts, adding tobacco to host diet is unnecessary when introducing $H$. hebetor into environments where tobacco is stored.

ACKNOWLEDgements. To the Conselho Nacional de Desenvolvimento Científico e Tecnológico $(\mathrm{CNPq})$ for the doctor degree scholarship granted to the first author. To MCTI/CT-Agro/ CNPq 38/2013 and Japan Tobacco International (JTI) for financial support.

\section{REFERENCES}

Aamer N., Hegazi E. \& Khafagi W. 2015: Reproductive capacity, sex ratio and longevity of the parasitoid, Bracon hebetor (Say) parasitizing the wax moth larvae, Galleria mellonella (L.). Egypt. J. Biol. Pest Contr. 25: 433-437.

Akinkurolere R.O., Boyer S., Chen H. \& Zhang H. 2009: Parasitism and host-location preference in Habrobracon hebetor (Hymenoptera: Braconidae): Role of refuge, choice, and host instar. - J. Econ. Entomol. 102: 610-615.

Ashworth J.R. 1993: The biology of Ephestia elutella. - J. Stored Prod. Res. 29: 199-205.

Athanassiou C.G. \& ArthuR F.H. 2018: Recent Advances in Stored Product Protection. Springer, Berlin, 273 pp.

Ayres M., Ayres M.J., Ayres D.L. \& Santos A.S. 2007: BioEstat 5.0 Aplicações Estatísticas na Area das Ciências Biológicas e Médicas. Sociedade Civil Mamirauá/CNPq, Belém, 324 pp.

Ayvaz A. \& KARABÖRKLÜ S. 2008: Effect of cold storage and different diets on Ephestia kuehniella Zeller (Lep.: Pyralidae). J. Pest Sci. 81: 57-62.

Bhavanam S.P. 2016: Effect of nutrient limitation on the Mediterranean flour moth, Ephestia kuehniella Zeller. PhD thesis, Massey University, Palmerston North, 182 pp.

Brower J.H., Smith L., Vail P.V. \& Flinn P.W. 1995: Biological control. In Subramanyam B. \& Hagstrum D.W. (eds): Integrated Management of Insects in Stored Products. Marcel Dekker, New York, pp. 223-286.

Coelho Filho A. 2010: Otimização da Criação de Anagasta kuehniella (Zeller, 1879), Hospedeiro Alternativo de Trichogramma spp., Baseando-se na Temperatura, Densidade Larval e Concentração de Dióxido de Carbono. MSc thesis, Escola Superior de Agricultura "Luiz de Queiroz", Universidade de São Paulo, Piracicaba, 81 pp.

Coelho Filho A. \& Parra J.R.P. 2013: The effect of rearing in different temperature regimes on the reproduction of Anagasta kuehniella (Lepidoptera: Pyralidae). - Environ. Entomol. 42: 799-804.

Collins W.K. \& Hawks S.N. 2011: Fundamentos da Produção do Tabaco de Estufa. Edunisc, Santa Cruz do Sul, 308 pp.

Darwish E., El-Shazly M. \& El-Sherif H. 2003: The choice of probing sites by Bracon hebetor Say (Hymenoptera: Braconidae) foraging for Ephestia kuehniella Zeller (Lepidoptera: Pyralidae). - J. Stored Prod. Res. 39: 265-276.

Eslampour L. \& ARAmiden S. 2016: Adult longevity, fertility and sex ratio of Habrobracon hebetor (Say) (Hymenoptera: Braconidae) parasitizing Ephestia kuehniella (Zeller) (Lepidoptera: Pyralidae): effect of host artificial diets. - J. Entomol. Zool. Stud. 4: 189-192.
FaAl-Mohammad-Ali H. \& Shishehbor P. 2013: Biological parameters of Bracon hebetor (Hym.: Braconidae) parasitizing Ephestia kuehniella (Lep.: Pyralidae): effect of host diet. - J. Crop Prot. 2: 411-419.

Farag N.A., Ismail I.A., Elbehery H.H.A., Abdel-Rahman R.S. \& ABdel-Raheem M.A. 2015: Life table of Bracon hebetor Say (Hymenoptera: Braconidae) reared on different hosts. - Int. J. Chemtech Res. 8: 123-130.

FAVARIS A.P. 2016: Isolamento do Cairomônio de Anagasta kuehniella Zeller (Lepidoptera: Pyralidae) responsável pela atração do parasitoide Habrobracon hebetor Say (Hymenoptera: Braconidae). MSc thesis, Escola Superior de Agricultura "Luiz de Queiroz”, Universidade de São Paulo, Piracicaba, 49 pp.

Gallo D., Nakano O., Neto S.S., Carvalho R.P.L., Baptista G.C., Berti Filho E., Parra J.R.P., Zucchi R.A., Alves S.B. Vendramim J.D. ET AL. 2002: Entomologia Agrícola. Fealq, Piracicaba, $920 \mathrm{pp}$.

Ghimire M.N. \& Phillips T.W. 2010: Suitability of different Lepidopteran host species for development of Bracon hebetor (Hymenoptera: Braconidae). - Environ. Entomol. 39: 449-458.

Ghimire M.N. \& Phillips T.W. 2014: Oviposition and reproductive performance of Habrobracon hebetor (Hymenoptera: Braconidae) on six different pyralid host species. - Ann. Entomol. Soc. Am. 107: 809-817.

Goulart M.M.P., Bueno A.F., Bueno R.C.O.F. \& Diniz A.F. 2011: Host preference of the egg parasitoids Telenomus remus and Trichogramma pretiosum in laboratory. - Rev. Bras. Entomol. 55: 129-133.

Guedes J.V.C. \& Costa I.F.D. 2006: Guia de Identificação e Manejo Integrado das Pragas e Doenças do Fumo. Orium, Santa Maria, $88 \mathrm{pp}$.

Hagstrum D.W. 1983: Self-provisioning with paralyzed hosts and age, density, and concealment of hosts as factors influencing parasitization of Ephestia cautella (Walker) (Lepidoptera: Pyralidae) by Bracon hebetor Say (Hymenoptera: Braconidae). - Environ. Entomol. 12: 1727-1732.

HARVEY J.A. 2005: Factors affecting the evolution of development strategies in parasitoid wasps: the importance of functional constraints and incorporating complexity. - Entomol. Exp. Appl. 117: 1-13.

Heimpel G.H. \& Mills N.J. 2017: Biological Control: Ecology and Applications. Cambridge University Press, Cambridge, $380 \mathrm{pp}$.

Jacomini D., Temponi L.G., Alves L.F.A., Silva E.A.A. \& Jorge T.C.M. 2016: Extrato de tabaco no controle do besouro cascudinho de aviário. - Pesquisa Agropec. Bras. 51: 680-683.

Kazumu K., Vicencio E.J.M. \& Kainoh Y. 2019: Differences in food plant species of the polyphagous herbivore Mythimna separata (Lepidoptera: Noctuidae) influence host searching behavior of its larval parasitoid, Cotesia kariyai (Hymenoptera: Braconidae). - Arthr. Plant Interact. 13: 49-55.

Kehrli P., Lehmann M. \& Bacher S. 2005: Mass-emergence devices: a biocontrol technique for conservation and augmentation of parasitoids. - Biol. Contr. 32: 191-199.

Kishani Farahani H., Ashouri A., Zibaee A., Abroon P. \& AlFORD L. 2016: The effect of host nutritional quality on multiple components of Trichogramma brassicae fitness. - Bull. Entomol. Res. 106: 633-641.

KRSTESKA V. 2014: Ephestia elutella Hüb. on tobacco. — Tobacco (Macedonia) 64: 70-77.

Kurtulus A., Pehlivan S., Achiri T.D. \& Atakan E. 2020: Influence of different diets on some biological parameters of the Mediterranean flour moth, Ephestia kuehniella Zeller (Lepidoptera: Pyralidae). — J. Stored Prod. Res. 85: 1-6. 
LIU S.S. \& JIANG L.H. 2003: Differential parasitism of Plutella $x y$ lostella (Lepidoptera: Plutellidae) larvae by the parasitoid $\mathrm{Co}$ tesia plutellae (Hymenoptera: Braconidae) on two host plant species. - Bull. Entomol. Res. 93: 65-72.

Lorini I., Krzyzanowski F.C., França-Neto J.B., Henning A.A. \& Henning F.A. 2015: Manejo Integrado de Pragas de Grãos e Sementes Armazenadas. Embrapa, Brasília, 84 pp.

Lucas E., Riudavets J. \& CAstañé C. 2015: A banker box to improve the impact of Habrobracon hebetor on stored product insects. - IOBC/WPRS Bull. 111: 403-407.

Magrini E.A., Botelho P.S.M., Parra J.R.P. \& Haddad M.L. 1993: Comparação de dietas artificiais para criação massal de Anagasta kuehniella (Zeller) (Lepidoptera: Pyralidae). Anais Soc. Entomol. Brasil 22: 361-371.

Magrini E.A., Parra J.R.P., Haddad M.L. \& Botelho P.S.M. 1995: Comparação de dietas artificiais e tipos de milho, para criação de Anagasta kuehniella (Zeller, 1879) (Lepidoptera: Pyralidae). - Sci. Agric. 52: 60-64.

Magro S.R. \& PARRA J.R.P. 2002: Criação in vitro de Bracon hebetor. In Parra J.R.P., Botelho P.S.M., Corrêa-Ferreira B.S. \& Bento J.M.S. (eds): Controle Biológico no Brasil: Parasitoides e Predadores. Manole, São Paulo, pp. 277-293.

Magro S.R., Dias A.B., Terra W.R. \& Parra J.R.P. 2006: Biological, nutritional, and histochemical basis for improving an artificial diet for Bracon hebetor Say (Hymenoptera: Braconidae). - Neotrop. Entomol. 35: 215-222.

McAuslane H.J., Vinson S.B. \& Williams H.J. 1990: Effect of host diet on flight behavior of the parasitoid Campoletis sonorensis (Hymenoptera: Ichneumonidae). - J. Entomol. Sci. 25: $562-570$.

Mohammadi S. \& Menrkhou F. 2020: Effects of various cereal flour on life table parameters of Ephestia kuehniella (Lepidoptera: Pyralidae). - J. Crop Prot. 9: 29-39.

Moratore C., Devicari M., Cunha S.S. \& Barcelos D. 2009: Utilização de Drosophila melanogaster como bioindicador na avaliação da letalidade de extrato de Nicotiana tabacum. Arq. Inst. Biol. 76: 471-474.

PARRA J.R.P. 2002: Comercialização de inimigos naturais no Brasil: uma área emergente. In Parra J.R.P., Botelho P.S.M., Corrêa-Ferreira B.S. \& Bento J.M.S. (eds): Controle Biológico no Brasil: Parasitoides e Predadores. Manole, São Paulo, pp. 343-349.

PARRA J.R.P. 2009: A evolução das dietas artificiais e suas interações em ciência e tecnologia. In Panizzi A.R. \& Parra J.R.P. (eds): Bioecologia e Nutrição de Insetos, Base para o Manejo Integrado de Pragas. Embrapa, Brasília, pp. 91-174.

PARRA J.R.P. 2014: Biological control in Brazil: An overview. Sci. Agric. 71: 345-355.

Parra J.R.P., Coelho Júnio A., Geremias L.D., Bertin A. \& Ramos C.J. 2014: Criação de Anagasta kuehniella, em Pequena Escala, para Produção de Trichogramma. Occasio, Piracicaba, 32 pp.

SAmpaio R.M. 2018: Controle Biológico: tecnologias na construção de oportunidades no Brasil. - Anális. Indicad. Agroneg. 13: $1-4$.

SERRA H.J.P. 1992: Bioecologia do Ectoparasito Habrobracon hebetor (Say, 1836) (Hymenoptera: Braconidae) em Anagasta kuehniella (Zeller, 1879) (Lepidoptera: Pyralidae). MSc the- sis, Escola Superior de Agricultura "Luiz de Queiroz”, Universidade de São Paulo, Piracicaba, 91 pp.

Silva A.B. \& Brito J.M. 2015: Controle biológico de insetospragas e suas perspectivas para o futuro. - Revista Agropec. Técnica 36: 248-258.

Singh D., Singh R.P. \& TRIPAThi C.P.M. 2006: Effect of host diet on life table statistics of Bracon hebetor (Say) (Hymenoptera: Braconidae). - Biol. Contr. 20: 165-168.

Solà M., Castañé C., Lucas E. \& Riudavets J. 2018: Optimization of a banker box system to rear and release the parasitoid Habrobracon hebetor (Hymenoptera: Braconidae) for the control of stored-product moths. - J. Econ. Entomol. 111: 2461-2466.

Soliman H.S. 1940: Studies in the biology of Microbracon hebetor Say (Hymenoptera: Braconidae). - Bull. Soc. Entomol. Egypte 24: 215-247.

Solis D.R., Habib M.E.E.D.M., Fernandes E.S.A., Hebling M.J.A. \& Silva T.F. 2006: Estudo comparativo do desenvolvimento de Anagasta kuehniella (Zeller, 1879) (Lepidoptera, Pyralidae) em três dietas artificiais. - Rev. Bras. Zoociênc. 8: $17-21$.

SouzA D.R. 2016: Isolamento Reprodutivo entre Linhagens Brasileiras de Helicoverpa zea $e$ Helicoverpa armigera (Lepidoptera: Noctuidae). MSc thesis, Escola Superior de Agricultura "Luiz de Queiroz", Universidade de São Paulo, Piracicaba, 16 pp.

Souza J.R., Boiça Júnior A.L., Perecin D., Costa J.T. \& Peixoto M.L. 2014: Preferência de Cotesia flavipes (Cameron, 1891) (Hymenoptera: Braconidae) por lagartas de Diatraea saccharalis (Fabricius, 1794) (Lepidoptera: Crambidae) alimentadas com diferentes cultivares de cana-de-açúcar. - Revista Ceres 61: 916-923.

Stein C.P. \& PARRa J.R.P. 1987: Aspectos biológicos de Anagasta kuehniella (Zeller, 1879) criada em dois substratos alimentares. — Anais Soc. Entomol. Brasil 16: 173-185.

Tognon R., SANT'ANA J. \& JAHNKE S.M. 2014: Influence of original host on chemotaxic behaviour and parasitism in Telenomus podisi Ashmead (Hymenoptera: Platygastridae). — Bull. Entomol. Res. 104: 781-787.

UJVÁRY I. 1999: Nicotine and other insecticidal alkaloids. In Yamamoto I. \& Casida J.E. (eds): Nicotinoid Insecticides and the Nicotinic Acetylcholine Receptor. Springer, Tokyo, pp. $29-69$.

Urrutia C.M.A., Wade M.R., Phillips C.B. \& Wratten S.D. 2007: Influence of host diet on parasitoid fitness: unravelling the complexity of a temperate pastoral agroecosystem. - Entomol. Exp. Appl. 123: 63-71.

Vacari A.M., Genovez G.S., Laurentis V.L. \& Bortoli S.A. 2012: Fonte proteica na criação de Diatraea saccharalis e seu reflexo na produção e no controle de qualidade de Cotesia flavipes. - Bragantia 71: 355-361.

Vasconcelos C.J. 2017: Desenvolvimento de uma Dieta Artificial para Criação de Anagasta kuehniella (Zeller, 1879) (Lepidoptera: Pyralidae), Hospedeiro Alternativo de Trichogramma spp. MSc thesis, Escola Superior de Agricultura "Luiz de Queiroz", Universidade de São Paulo, Piracicaba, 44 pp.

Received November 4, 2019; revised and accepted March 9, 2020 Published online April 28, 2020 